\title{
Mapping the upper mantle discontinuities beneath China with teleseismic receiver functions
}

\author{
Xuzhang Shen ${ }^{1,2,3}$, Huilan Zhou ${ }^{1}$, and Hitoshi Kawakatsu ${ }^{2}$ \\ ${ }^{1}$ Laboratory of Computational Geodynamics, Graduate University of the Chinese Academy of Sciences, Beijing, 100049, China \\ ${ }^{2}$ Earthquake Research Institute, University of Tokyo, 1-1-1 Yayoi, Bunkyo-ku, Tokyo 113-0032, Japan \\ ${ }^{3}$ Lanzhou Institute of Seismology, China Earthquake Administration, Lanzhou, 730000, China
}

(Received December 4, 2007; Revised March 28, 2008; Accepted April 10, 2008; Online published August 4, 2008)

\begin{abstract}
We used teleseismic body waves recorded at stations of the Chinese Center of Digital Seismic Network to map the upper mantle discontinuities beneath continental China. The CRUST2.0 and an S-tomography model beneath each station were combined with the one-dimensional tracing method to convert time series of radial receiver functions to depth series. Clear signatures corresponding to the 410 - and $660-\mathrm{km}$ discontinuities (' 410 ' and '660') are visible at almost all of the stations. The average $S$ velocity contrast of ' 410 ' beneath the study area is close to the global average, but that for ' 660 ' is smaller than the global average. The average depth of ' 410 ' is $413 \mathrm{~km}$, and the peak-to-peak topography is about $36 \mathrm{~km}$, with regional depressions that correlate with the Datong quaternary volcano in northern China. The ' 660 ' topography exhibits a peak-to-peak variation of about $43 \mathrm{~km}$, and its average depth is $669 \mathrm{~km}$; the depressions of the '660' in northeastern, southeastern and northern China are well correlated with the past subduction around the Pacific Ocean and Philippine Sea. The width of the transition zone is also increased in the region with the deeper ' 660 '. Our results would appear to indicate that there may be a low-velocity layer below a depth of approximately $600 \mathrm{~km}$ that may be the accumulated garnetite layer of an ancient crust above the ' 660 '.
\end{abstract}

Key words: Mantle discontinuity, China, receiver function, low-velocity layer.

\section{Introduction}

The subduction systems of the Pacific and Philippine Sea plates, which are located in the eastern part of China, cause island arcs, marginal seas and continental rift zones. Studies have shown that the western Pacific slab stagnates beneath the northeast region of China (Fukao et al., 2001; Huang and Zhao, 2006) and may locally penetrate into the lower mantle (Li and Yuan, 2003). The Indian plate collides with the Eurasian plate in the southwestern part of China, resulting in the Tibetan plateau and the Himalayas, the world's highest mountain range, and the thickest continental crust in the world. Various tomographic studies have shown that the Datong quaternary volcano (DQV, Fig. 1) in northern China may be related with the subducting Pacific slab (Zhao and Lei, 2004) and that there may be a plume beneath the Hainan region (Lebedev and Nolet, 2003) in southern China. Investigation of the topography of upper mantle discontinuities will facilitate a better understanding of the evolution and dynamics of the slabs and clarify the mechanism of volcanisms and plumes.

The receiver function (RF) method is an excellent tool for detecting seismic discontinuities in the upper mantle through the analysis of $P$-to- $S$ conversions (Langston, 1979). There have been many case studies carried out to learn more about the Chinese continent, including studies

Copyright (c) The Society of Geomagnetism and Earth, Planetary and Space Sciences (SGEPSS); The Seismological Society of Japan; The Volcanological Society of Japan; The Geodetic Society of Japan; The Japanese Society for Planetary Sciences; TERRAPUB. on the depth of the mantle discontinuities beneath China (Niu and Kawakatsu, 1998; Yang and Zhou, 2001), on the lithospheric and upper mantle structure of southern Tibet (Yuan et al., 1997), and on a complex structure of the upper mantle discontinuities beneath northeastern China (Niu and Kawakatsu, 1996; Lebedev et al., 2002; Ai et al., 2003). Although important results have been obtained from such studies, resolution of the topography of upper mantle discontinuities can be improved by making use recent observation data.

Here, we report our analysis of the receiver functions of 46 stations comprising part of the Chinese Center of Digital Seismic Network (CCDSN). Using the CRUST2.0 model (Bassin et al., 2000) and the $S$-wave tomography model (Grand, 2002) beneath every station, we converted the time series of receiver functions to depth series and then analyzed these depth series to obtain the depths of the upper mantle discontinuities. The results presented here reveal a new topography of the upper mantle discontinuities beneath continental China. The new data were compared to the result of the earlier studies, and regional earth models were referred to in order to estimate the depth of the discontinuities.

\section{Data}

Data were compiled from a total of 48 broadband seismic stations comprising part of the CCDSN, with an average distance of $500-600 \mathrm{~km}$ between two adjacent stations (Fig. 1). Due to equipment failures and other un- 


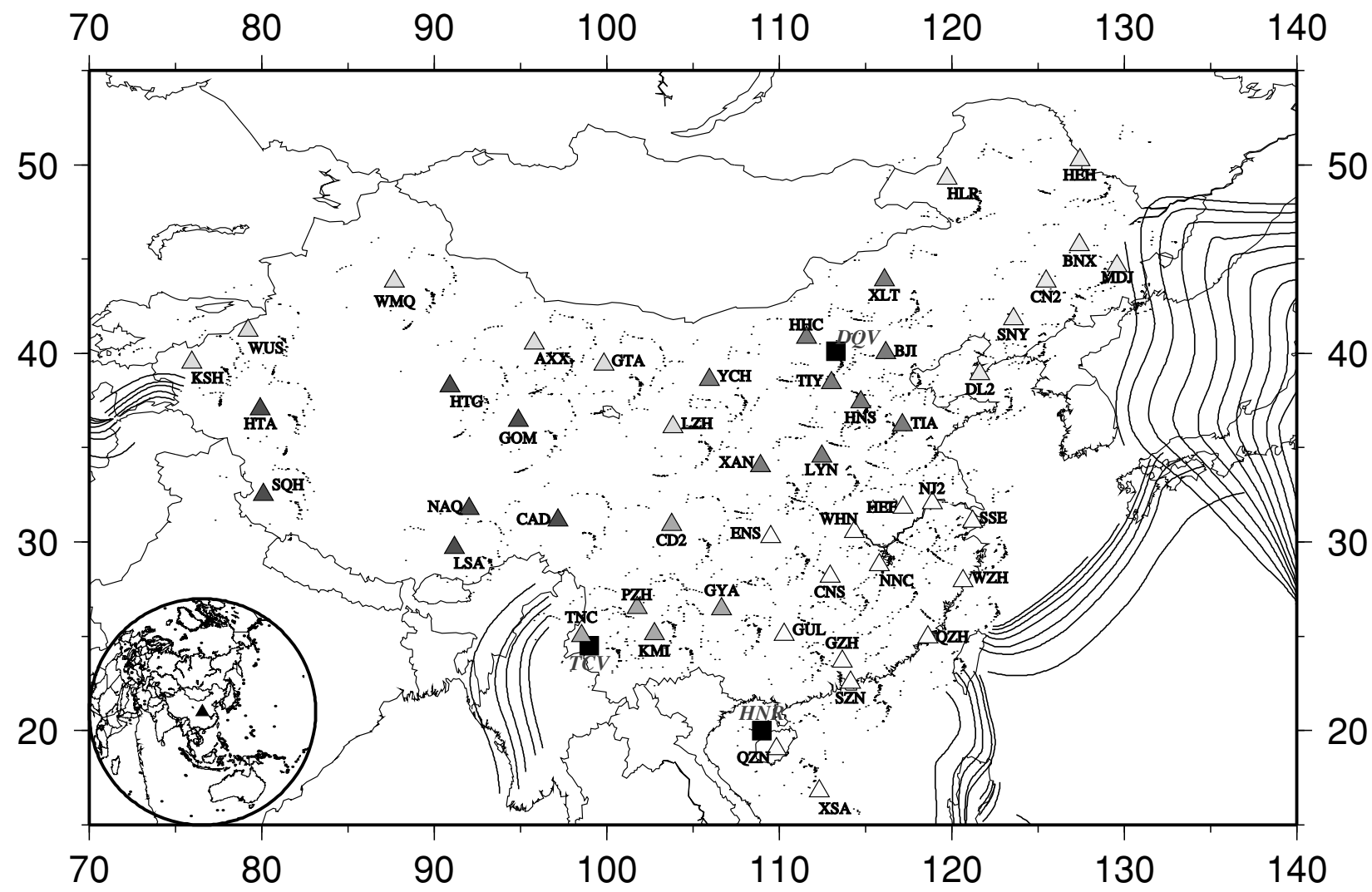

$\triangle$ Northeast $\triangle$ Southeast $\Delta$ North China $\triangle$ Southwest $\Delta$ Tibet $\triangle$ Nothwest

Fig. 1. Location of stations and events. Triangles indicate the location of stations, the letters beside them are the names of the stations and the different colors mean that the station is in different regions. Squares represent the approximate location of volcanoes and a possible hot plume: DQV, Datong quaternary volcano; TCVs, Tengchong volcanoes; HNR, Hainan region (Lebedev and Nolet, 2003). Black curves are contours of the subducting slab around China (Gudmundsson and Sambridge, 1998). Small black dots are the $P 660$ s pierce points of all time series (ORFs). The distribution of earthquakes used in this paper is shown at the bottom left of the figure. The triangle indicates the centroid location of the seismic network, and the black points are the event locations.

known causes, the records of stations NAQ in Tibet and XSA in southernmost China are not available. We collected records of teleseismic events with a magnitude of $M_{\mathrm{s}}>5.5$ that occurred between November 2003 and November 2005 with epicentral distances in the range of $30-90^{\circ}$. We selected records that have an acceptable signal-to-noise ratio and clear onset of the $P$-wave. Figure 1 shows the locations of the stations, earthquakes and the entire pierce points of $P 660 s$ ( $P d s$ refers to a $P$-to- $S$ converted phase at a depth of $d \mathrm{~km}$ ) of the observed receiver functions (ORFs). The ORFs were calculated using the iterative deconvolution method in the time domain (Ligorria and Ammon, 1999). A low-pass Gaussian filter with the half-width constant $\alpha=1.5$ is applied; the corner frequency of the filter is $0.28 \mathrm{~Hz}$. In total, $4760 \mathrm{ORFs}$ were used in our study.

\section{Methodology}

\subsection{Moveout correction of receiver functions}

A distance moveout correction for $P$-to- $S$ converted phases was adapted (Yuan et al., 1997) in order to focus on the $P d s$ phases at each station. Based on the IASP91 model (Kennett and Engdahl, 1991), this correction shifts all of the $P d s$ phases to times of the same phases for an epicentral distance of $65^{\circ}$. The multiples can then be suppressed by stacking all of the corrected ORFs. The boot- strap re-sampling method (Efron and Tibshirani, 1998) was used to estimate the error of the stacked results: the number of samples in each stacking equals to the number of ORFs, and the stacking is applied for 100 times to evaluate the standard deviation. A value twice the standard deviation, which gives a $95 \%$ confidence detection level, was used to show the stacked results.

\subsection{Converting ORFs to the depth domain}

The $P$-to- $S$ converted phases of 410 - and $660-\mathrm{km}$ depths were clearly visible at most of the stations (Fig. 2(a)), thereby providing strong proof for the existence of these two upper mantle discontinuities beneath continental China. In order to determine the depth of the discontinuities, we attempted to correct for the effect of the three-dimension (3-D) structure by referring to the CRUST2.0 model (Bassin et al., 2000) for both $V_{p}$ and $V_{s}$ of the crust. For the mantle, the 3-D shear velocity tomography model of Grand (Grand, 2002, 2006 personal communication) was referred as follows: (1) the average 1-D $V_{s}$ model was taken from that of the Grand model, and then the average 1-D $V_{p}$ model was constructed, assuming the $V_{p} / V_{s}$ ratio of IASP91; (2) local 1-D $V_{s}$ models beneath stations were constructed based on the Grand 3-D model; (3) assuming that the local deviations are due to thermal anomaly, the local $V_{s}$ anomalies were converted to the local $V_{p}$ anomalies using the relation 


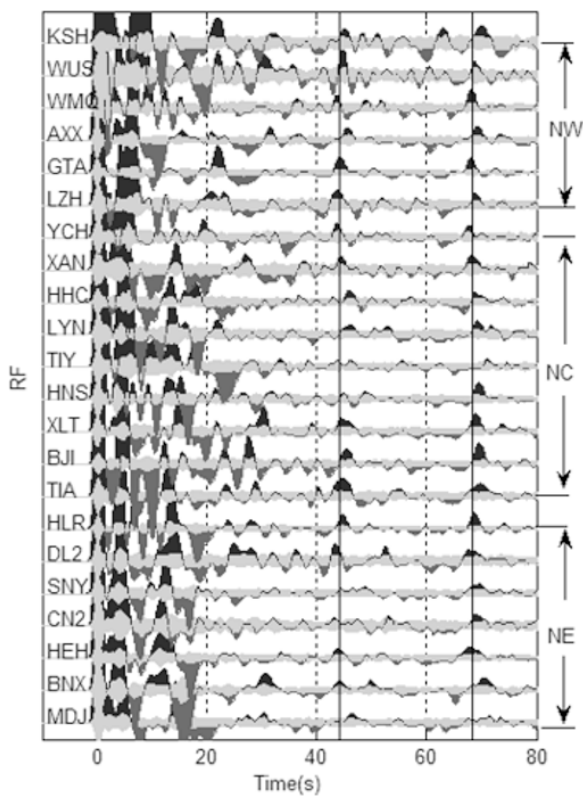

(a)
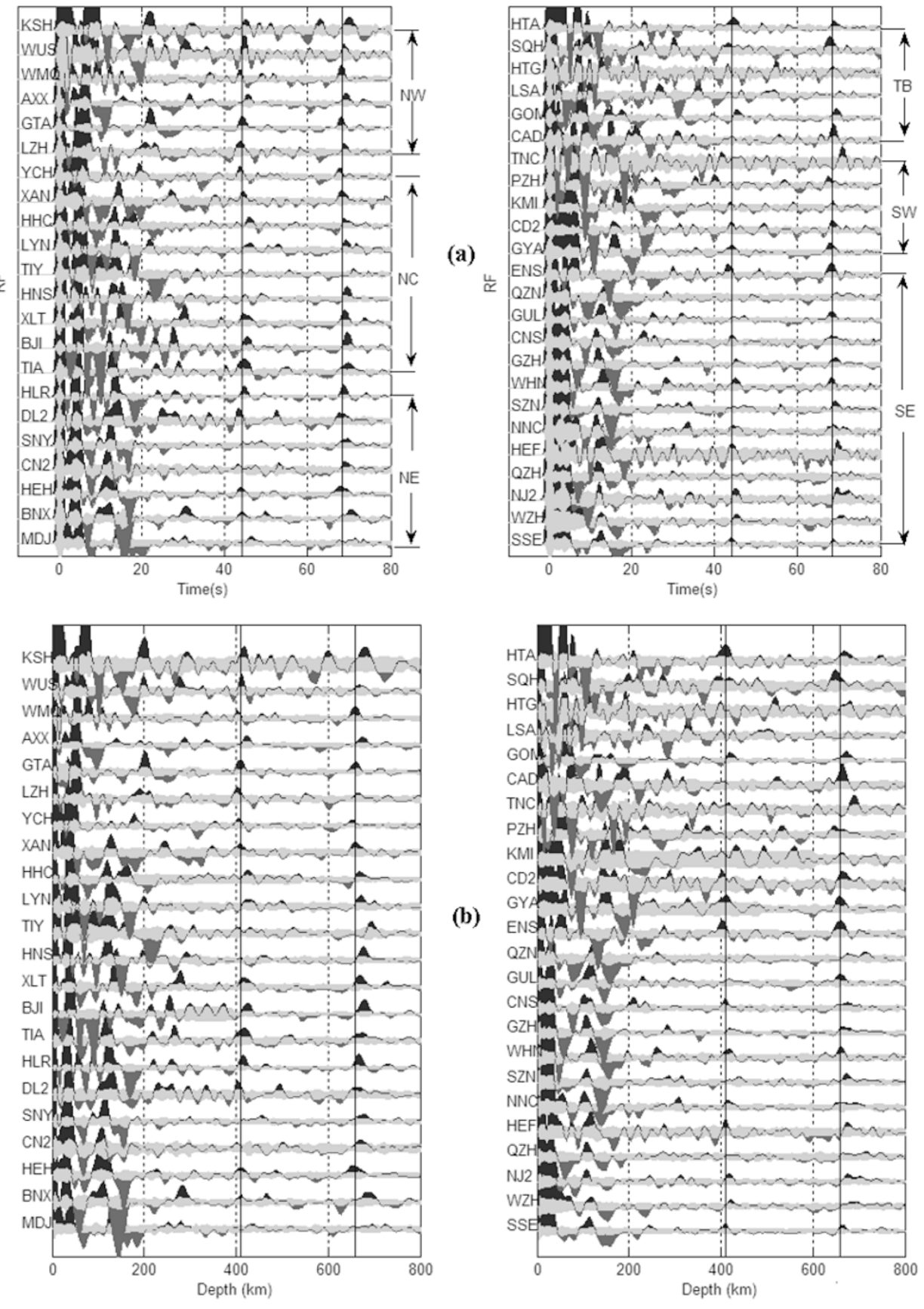

Fig. 2. (a) Waveforms of the stacked moveout-corrected ORFs of every station. The gray shadow indicates the value of twice the standard deviation estimated by the bootstrap method; the letters on the left are station codes, and the letters on the right represent the region (Fig. 1) codes: NE, northeast; NC, northern China; NW, northwest; SE, southeast; SW, southwest; TB, Tibet. The black lines show the expected timings of $P 410$ s and $P 660 s$ predicted by IASP91. (b) Stacked results of converted depth series: the amplitude of the depth series is obtained from ORF (detailed explanations can be found in the text); the black lines show a depth of $410 \mathrm{~km}$ and $660 \mathrm{~km}$.

$R=d \ln V_{s} / d \ln V_{p}$ given by Karato (Karato, 1993, 2006 personal communication); (4) local $V_{p}$ anomalies were used to construct local 1-D $V_{p}$ models.

The model is divided into thin layers; the thickness of the layers is $2 \mathrm{~km}$ in the crust and $4 \mathrm{~km}$ in the upper mantle. The travel times of the $P$ and $P d s$ phases are calculated with the 1-D ray tracing method, and then the relative time of $P d s$ phases of different depths to the $P$ phase can be used to convert each time series (ORF) to a depth series. We averaged amplitudes before and after $0.3 \mathrm{~s}$ of each ORF to construct the depth series $(2-\mathrm{km}$ and $4-\mathrm{km}$ intervals for the crust and the upper mantle, respectively); this averaging time window of $0.6 \mathrm{~s}$ corresponds to an average depth of approximately $6 \mathrm{~km}$, which is a little larger than the sampling intervals of the depth series. This procedure smoothes ORFs without losing information as $0.6 \mathrm{~s}$ is below the corner period of the low-pass filter and thus improves the stability of the results. The $P d s$ phase signals could also be strengthened by stacking the depth series for each station, and the bootstrap method is still used to evaluate the error. Figure 2(b) shows the depth series with error bounds for all stations. 

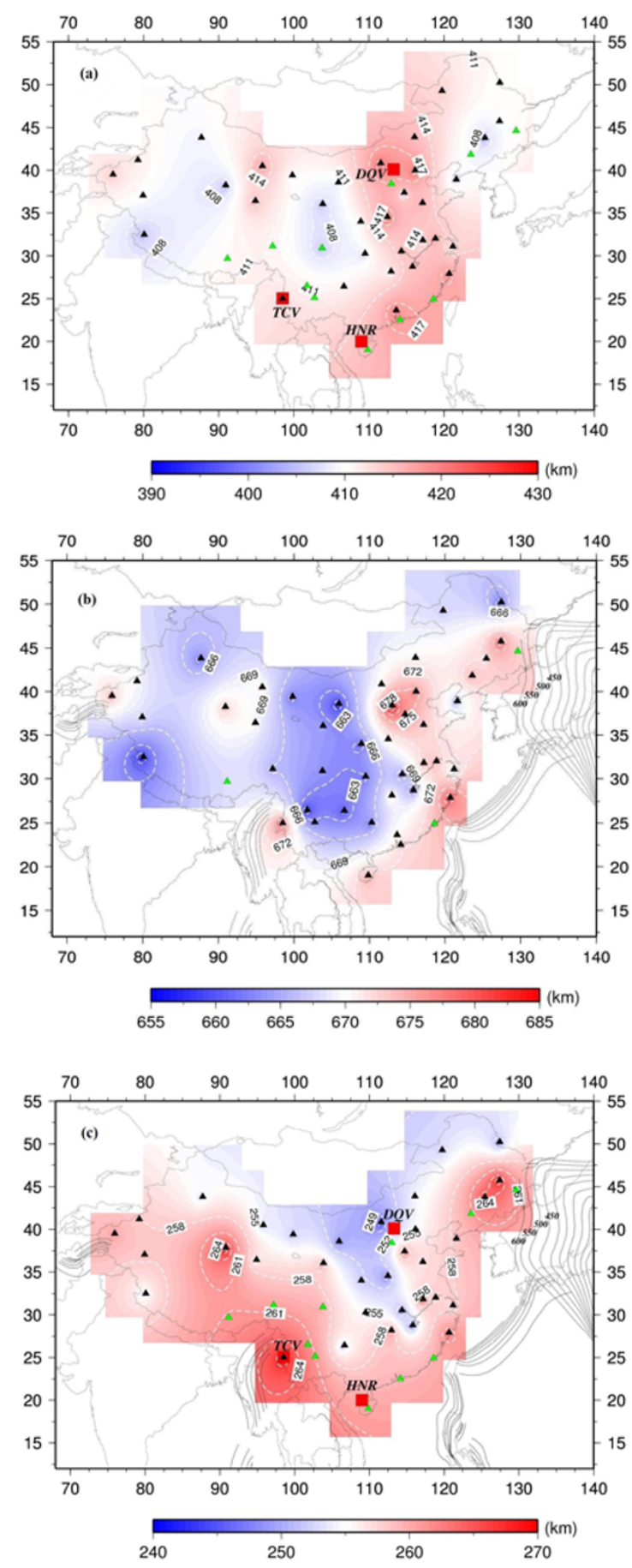

Fig. 3. (a) Topography of ' 410 ', (b) topography of ' 660 ', (c) map of transition zone thickness. Black triangles show the location of the stations beneath which the depths of ' 410 ' or ' 660 ' are determined. Green triangles indicate the stations beneath which the depths of ' 410 ' or ' 660 ' are not recognized. Black curves in (b) and (c) show the contours of the subducting slab around China (Gudmundsson and Sambridge, 1998); the depths of the Pacific slab are also marked.

\section{Results}

The peaks near depths of 410 and $660 \mathrm{~km}$ are very clear for the most of stations (Fig. 2(b)). However, the peaks near $410 \mathrm{~km}$ are ambiguous or are multiples of shallower structures at stations MDJ, SNY, TIY, QZH, SZN, QZN, GUL, $\mathrm{KMI}, \mathrm{PZH}, \mathrm{CAD}$ and LSA; the same is true for peaks near $660 \mathrm{~km}$ at stations MDJ, QZH and LSA. It was difficult to determine the depth of the discontinuities for these stations, so we did not attempt to do so in our study. Table 1 lists the detailed depths of the $410-\mathrm{km}$ and $660-\mathrm{km}$ discontinuities (hereafter '410' and '660', respectively) observed at the stations which show clear signals. Figure 3(a) and (b) shows the topography of '410' and '660' respectively, and the thickness of the transition zone $\left(H_{\mathrm{TZ}}\right)$ is shown in Fig. 3(c).

The depression of ' 410 ' is visible under the region around the DQV; a tomography (Zhao and Lei, 2004) indicates that this volcano may be associated with the deep dehydration process of the subducted Pacific slab and the convective circulation process in the mantle wedge. In southern China, especially in southwestern China, it is difficult to determine $P 410$ s at many stations (green triangles in Fig. 3(a)). The tomography results here show that there is a low-velocity zone between depths of 238 and $410 \mathrm{~km}$ in southeastern China (Fukao et al., 2001) and that there even may exist a plume with it origin in the lower mantle beneath the Hainan region (HNR) (Lebedev and Nolet, 2003). On the other hand, the active Tengchong volcanoes (TCVs) are located in southwestern China. All of these results and phenomena seem to suggest the possible existence of a high temperature region beneath these areas that may result in the complication of ' 410 ' in this area.

The ' 660 ' discontinuity is distinctly deeper in a trianglelike region in eastern China delimited by the stations BNX, TIY and WZH than in other regions. This result is consistent with previous results of receiver function analyses (Niu and Kawakatsu, 1998; Li and Yuan, 2003) and correlates well with the hypothesis of a stagnant Pacific slab and Philippine Sea slab suggested by tomography (Fukao et al., 2001; Zhao and Lei, 2004; Huang and Zhao, 2006). The depths of ' 660 ' beneath TNC and KSH exceed $680 \mathrm{~km}$, but these depressions are very local, and more dense data are needed to verify the results. In other areas, the depths of ' 660 ' fluctuate within a narrow range.

Based on the $H_{\mathrm{TZ}}$ results (Fig. 3(c)), the area with the obviously thicker transition zone in northeastern and eastern China is well correlated with the depression of ' 660 ' in the region. This result further supports the existence of the stagnant Pacific and Philippine Sea slabs in this area. In the other regions, the variation in the thickness of the transition zone may only reflect local features because of the sparse station coverage; consequently, this topic is beyond the scope of our study.

\section{Discussion}

Niu and Kawakatsu (1998) analyzed broadband seismic waveforms of 11 stations belonging to CDSN with a polarized filter to determine the absolute depths of the mantle transition zone discontinuities beneath China. Our results are basically consistent with theirs, with the exception of those for station BJI, and the $P 410$ s and $P 660 s$ of our ORF are very clear (Fig. 2(a)) and consistent with those of $\mathrm{Li}$ et al. (2000). The complicated structure of ' 660 ' beneath MDJ has been suggested previously but interpreted differently (Niu and Kawakatsu, 1996; Lebedev et al., 2002; Ai et al., 2003). Our results also show several weak peaks near a depth of $660 \mathrm{~km}$, but as our data is based on the stacking 
Table 1. Estimated depths of ' 410 ' and ' 660 ', $R_{410}, R_{660}$ and thickness of the transition zone. $O$, Observed depths of ' 410 ' and ' 660 '; $H_{\mathrm{TZ}}$, thickness of transition zone; $E$, error estimated by the boot strap method (two standard deviations); $R_{410}$, amplitude ration of $P 410 s$ to $P$; $R_{660}$, amplitude ration of $P 660$ s to $P ; N($ evt $)$, the number of events analyzed for the station; - , the phase is either ambiguous or multiple.

\begin{tabular}{|c|c|c|c|c|c|c|c|c|c|c|c|}
\hline \multirow{2}{*}{$\begin{array}{l}\text { Station } \\
\text { code }\end{array}$} & \multirow{2}{*}{ Lon $\left(^{\circ}\right)$} & \multirow{2}{*}{ Lat $\left(^{\circ}\right)$} & \multicolumn{2}{|c|}{ '410’ (km) } & \multirow{2}{*}{$R_{410}$} & \multicolumn{2}{|c|}{ ‘660’ (km) } & \multirow{2}{*}{$R_{660}$} & \multicolumn{2}{|c|}{$H_{\mathrm{TZ}}(\mathrm{km})$} & \multirow{2}{*}{$N($ evt $)$} \\
\hline & & & $(O$ & E) & & $(O$ & $E)$ & & $(O$ & $E)$ & \\
\hline $\mathrm{AXX}$ & 95.800 & 40.514 & 423 & 1.5 & 0.031 & 674 & 2.4 & 0.030 & 251 & 3.4 & 140 \\
\hline BJI & 116.168 & 40.018 & 425 & 2.5 & 0.047 & 679 & 2.0 & 0.058 & 254 & 3.4 & 126 \\
\hline $\mathrm{BNX}$ & 127.405 & 45.740 & 410 & 3.3 & 0.035 & 685 & 5.1 & 0.042 & 275 & 6.2 & 75 \\
\hline CAD & 97.500 & 31.000 & - & - & - & 664 & 2.0 & 0.088 & - & - & 88 \\
\hline $\mathrm{CD} 2$ & 103.758 & 30.910 & 403 & 3.2 & 0.046 & 664 & 2.0 & 0.048 & 261 & 6.2 & 90 \\
\hline $\mathrm{CN} 2$ & 125.448 & 43.801 & 402 & 5.5 & 0.025 & 671 & 5.0 & 0.033 & 269 & 8.2 & 62 \\
\hline CNS & 112.931 & 28.182 & 409 & 2.2 & 0.033 & 675 & 8.8 & 0.021 & 266 & 10.8 & 86 \\
\hline DL2 & 121.628 & 38.906 & 404 & 2.0 & 0.052 & 662 & 7.6 & 0.035 & 258 & 7.4 & 107 \\
\hline ENS & 109.487 & 30.272 & 405 & 3.2 & 0.054 & 660 & 3.1 & 0.060 & 255 & 3.5 & 122 \\
\hline GOM & 94.873 & 36.432 & 419 & 3.4 & 0.032 & 672 & 1.9 & 0.039 & 253 & 3.8 & 109 \\
\hline GTA & 99.814 & 39.411 & 409 & 2.4 & 0.045 & 660 & 2.2 & 0.043 & 251 & 3.5 & 156 \\
\hline GUL & 110.294 & 25.076 & - & - & - & 659 & 3.0 & 0.036 & - & - & 90 \\
\hline GYA & 106.664 & 26.459 & 411 & 4.0 & 0.040 & 658 & 3.0 & 0.049 & 247 & 4.3 & 112 \\
\hline $\mathrm{GZH}$ & 113.344 & 23.087 & 424 & 6.6 & 0.023 & 670 & 7.0 & 0.028 & 670 & 7.1 & 91 \\
\hline HEF & 117.168 & 31.836 & 410 & 2.7 & 0.043 & 675 & 6.7 & 0.046 & 265 & 7.3 & 69 \\
\hline $\mathrm{HEH}$ & 127.410 & 50.250 & 410 & 6.1 & 0.025 & 655 & 6.1 & 0.029 & 245 & 6.4 & 107 \\
\hline $\mathrm{HHC}$ & 111.564 & 40.849 & 427 & 6.7 & 0.031 & 668 & 1.5 & 0.025 & 241 & 7.2 & 138 \\
\hline HLR & 119.740 & 49.267 & 415 & 1.8 & 0.055 & 666 & 1.1 & 0.059 & 251 & 2.1 & 131 \\
\hline HNS & 114.708 & 37.418 & 409 & 4.1 & 0.018 & 677 & 1.8 & 0.047 & 268 & 5.8 & 121 \\
\hline HTA & 79.917 & 37.067 & 411 & 3.5 & 0.083 & 670 & 3.9 & 0.042 & 259 & 4.6 & 61 \\
\hline HTG & 90.760 & 37.860 & 400 & 3.5 & 0.035 & 677 & 6.3 & 0.024 & 277 & 8.5 & 97 \\
\hline KMI & 102.740 & 25.123 & - & - & - & 663 & 4.0 & 0.034 & - & - & 116 \\
\hline $\mathrm{KSH}$ & 75.923 & 39.517 & 417 & 3.3 & 0.056 & 680 & 5.3 & 0.078 & 263 & 8.2 & 100 \\
\hline LSA & 91.150 & 29.700 & - & - & - & - & - & - & - & - & 116 \\
\hline LYN & 112.468 & 34.550 & 428 & 6.6 & 0.019 & 671 & 1.9 & 0.038 & 243 & 6.5 & 114 \\
\hline $\mathrm{LZH}$ & 103.844 & 36.087 & 403 & 3.8 & 0.048 & 666 & 3.6 & 0.030 & 263 & 4.5 & 118 \\
\hline MDJ & 129.592 & 44.616 & - & - & - & - & - & - & - & - & 96 \\
\hline NJ2 & 118.854 & 32.052 & 419 & 2.6 & 0.036 & 675 & 9.9 & 0.031 & 256 & 5.8 & 78 \\
\hline NNC & 115.801 & 28.778 & 415 & 4.7 & 0.025 & 660 & 7.6 & 0.022 & 245 & 11.5 & 77 \\
\hline $\mathrm{PZH}$ & 101.743 & 26.504 & - & - & - & 649 & 6.8 & 0.048 & - & - & 113 \\
\hline QZH & 118.592 & 24.943 & - & - & - & - & - & - & - & - & 94 \\
\hline QZN & 109.843 & 19.029 & - & - & - & 677 & 6.9 & 0.023 & - & - & 93 \\
\hline SNY & 123.578 & 41.828 & - & - & - & 677 & 6.1 & 0.026 & - & - & 123 \\
\hline $\mathrm{SQH}$ & 80.080 & 32.500 & 401 & 9.5 & 0.035 & 650 & 2.7 & 0.070 & 249 & 12.0 & 80 \\
\hline SSE & 121.187 & 31.096 & 410 & 2.5 & 0.032 & 665 & 2.0 & 0.019 & 255 & 3.0 & 112 \\
\hline SZN & 114.080 & 22.320 & - & - & - & 673 & 2.2 & 0.039 & - & - & 88 \\
\hline TIA & 117.124 & 36.211 & 417 & 5.9 & 0.046 & 673 & 6.9 & 0.030 & 256 & 9.1 & 115 \\
\hline TIY & 113.017 & 38.430 & - & - & - & 693 & 2.4 & 0.036 & - & - & 122 \\
\hline TNC & 98.520 & 25.029 & 414 & 6.9 & 0.037 & 690 & 2.1 & 0.057 & 276 & 7.2 & 101 \\
\hline WHN & 114.350 & 30.544 & 416 & 4.9 & 0.048 & 661 & 1.5 & 0.046 & 245 & 5.0 & 98 \\
\hline WMQ & 87.695 & 43.821 & 408 & 7.6 & 0.032 & 659 & 1.7 & 0.050 & 251 & 7.8 & 118 \\
\hline WUS & 79.211 & 41.202 & 412 & 0.4 & 0.078 & 670 & 5.4 & 0.027 & 258 & 5.6 & 88 \\
\hline WZH & 120.664 & 27.926 & 421 & 4.3 & 0.028 & 688 & 7.4 & 0.020 & 267 & 7.9 & 99 \\
\hline XAN & 108.924 & 34.031 & 408 & 3.5 & 0.048 & 659 & 3.2 & 0.040 & 251 & 4.8 & 87 \\
\hline XLT & 116.074 & 43.893 & 415 & 4.8 & 0.036 & 670 & 2.2 & 0.044 & 255 & 5.0 & 123 \\
\hline $\mathrm{YCH}$ & 105.930 & 38.603 & 407 & 5.3 & 0.036 & 653 & 2.3 & 0.029 & 246 & 5.9 & 113 \\
\hline
\end{tabular}

of ORFs from all directions, we were unable to discriminate between the different models. A dense network observation study, such as that of the proposed NECESSArray (NorthEast China Extended SeiSmic Array; planned by an international group of scientists of China-Japan-USA) may be necessary for this purpose.

The amplitudes of converted phases of ORFs are mainly controlled by the velocity contrast of the discontinuities, but they also depend on the epicenter distance (Ammon,
1991). Thus, the information on amplitudes can be distorted by directly stacking moveout-corrected ORFs of different epicenter distances. We corrected the amplitudes of ORFs approximately on the base of the transmission coefficient of $P$-to- $S$ conversions of the IASP91 model for different distances before applying the moveout correction and stacking. Figure 4 shows the amplitude ratio of the $P d s$ to $P$ phases $\left(R_{d}\right)$ beneath each station, which is listed in Table 1. Although there is a large scatter in the data, the av- 


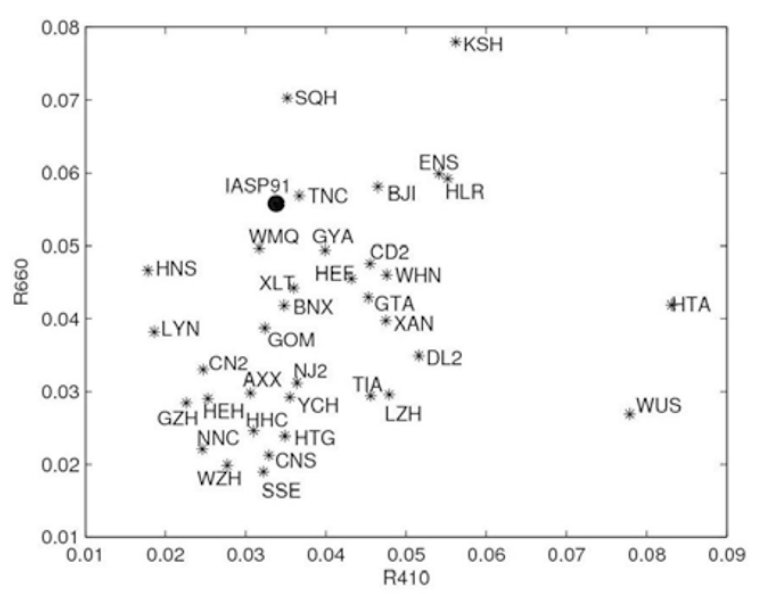

Fig. 4. Amplitude ratios of $P 410 s$ and $P 660 s$ to the $P$ phase for each station. The circle shows the corresponding ratio of IASP91.

erages of $R_{410}$ and $R_{660}$ are $3.98 \pm 1.44 \%$ and $4.00 \pm 1.55 \%$ in the study area, respectively. These two ratios are $3.38 \%$ and $5.58 \%$, respectively, for synthetic RFs calculated for IASP91 with the PREM's $Q$ model (Dziewonski and Anderson, 1981). This result suggests that the $S$ velocity contrast of the ' 410 ' beneath the study area is close to the global average, while that of the '660' is small, although a part may be attributed to the lateral variation of the depth of ' 660 ' because the distance of different pierce points of $P 660$ s is larger than $P 410$ s.

In addition to the $P 410$ s and $P 660$ s phases, we also noticed signatures above the noise level with a negative amplitude around $60 \mathrm{~s}$ in many of the stacked ORFs (Fig. 2(a)). There are four possible explanations for a negative phase near $60 \mathrm{s:}$ (1) a $P$-to- $S$ converted phase at a discontinuity at a depth of approximately $600 \mathrm{~km}$ with a $S$ velocity decrease; (2) a first-order reverberation phase of a high-velocity discontinuity at a depth of approximately $130 \mathrm{~km}$; (3) a first-order reverberation phase of a lowvelocity discontinuity at a depth of approximately $180 \mathrm{~km}$; (4) a second-order reverberation phase of a high-velocity discontinuity at a depth of approximately $70 \mathrm{~km}$. For the second and third model, there should be corresponding positive and negative phases near $15 \mathrm{~s}$ and $20 \mathrm{~s}$, respectively on the ORFs. As we do not find these phases clearly in our results, these two possibilities are unlikely. In Tibet, the moho depth reaches $70 \mathrm{~km}$ (Bassin et al., 2000), and it may produce a negative phase at approximately 60 . However, in other regions, the first model is most likely to explain this negative phase.

In order to examine the regional characteristics of this negative phase signature before $P 660 s$, we divided the whole region into six parts (names of parts are listed in Fig. 2(a)). The moveout-stacked ORFs of each station (Fig. 2(a)) are stacked straightly to produce average RFs of different regions (Fig. 5(a)) and stacked in alignment with the $P 660$ s phases (Fig. 5(b); the bootstrap method is used to estimate the error). In both of the cases, the negative phases or negative trends before $P 660 s$ can be found in every region, so this negative phase signature appears to be not just a local feature but more general feature beneath China.
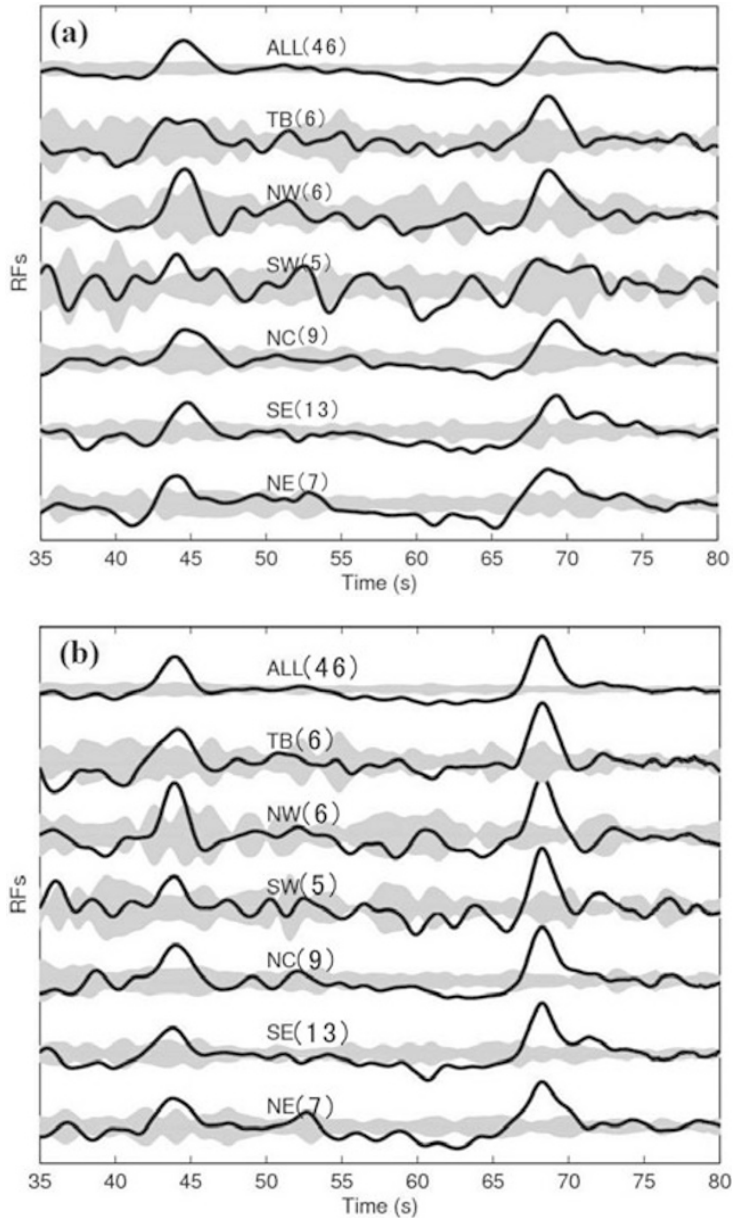

Fig. 5. Regional averages of moveout-stacked ORFs of Fig. 2(a). (a) ORFs are stacked straightly. The letters represent regions (with the number of stations), and 'ALL' indicates the average of the results for all the stations; the gray shadow represents the error (the $95 \%$ confidence level from bootstrap resampling method). The bootstrap error estimates tend to over-estimate standard deviations for a small amount of data. (b) ORFs are aligned by the peaks of the $P 660 \mathrm{~s}$ phase and stacked.

In northeastern China, where the presence of the stagnant slabs have been inferred (Fukao, 2001; Huang and Zhao, 2006), a common observation has been that the fastest velocity anomalies are located in the middle of the transition rather than at the bottom. In such a region, this negative phase may correspond to the signature of the bottom boundary of the fast-velocity stagnant slab. Such an interpretation, however, cannot explain why we observed similar negative phase signatures in other areas in an apparently ubiquitous manner beneath the Chinese continent.

We therefore suggest that a low-velocity layer (LVL) exists above the $660-\mathrm{km}$ discontinuity beneath the Chinese continent. Figure 5(a) and (b) shows that the times of the negative phases relative to the $P 660$ s may be quite variable in different regions; consequently, the thickness and property of the layer may be variable. A similar LVL has been reported beneath southern Africa (Shen and Blum, 2003). These researchers also observed a relatively small velocity contrast at ' 660 ' beneath southern Africa, similar to what we found beneath China, and they attributed it to the exsolution of Ca-perovskite in former oceanic crust above the ' 660 ' and the associated small volume fraction of ring- 
woodite there. The tomographic models and tectonic reconstructions show the ancient Tethys lithosphere thrusts beneath the Eurasia, and the slab detachment reached into the lower mantle (Hafkenscheid et al., 2006). Numerical simulations and theoretical analyses have shown that the oceanic crust may decouple from the subducted slab under the conditions of '660' (van Keken et al., 1996; Karato, 1997). We therefore tentatively suggest that the LVL observed ubiquitously beneath China may be a result of the accumulation of the Tethys crust (plus the Pacific crust). It may be also related with the accumulation of the delaminated continental crust (Karato, 2003). Further research is obviously needed to substantiate this hypothesis because the phases of LVL are not very strong.

\section{Conclusion}

We estimated the depths of the upper mantle discontinuities beneath China with teleseismic ORFs. There is a depression of ' 410 ' around the Datong quaternary volcano; the depression of ' 660 ' in eastern China is highly consistent with the stagnating Pacific and Philippine Sea slab, as indicated by tomography and receiver functions. The contrast of $S$ velocity of ' 410 ' is close to the global earth average, while that of ' 660 ' is smaller. Our results appear to indicate the possible presence of a low-velocity layer above the $660-\mathrm{km}$ discontinuity beneath the most of stations. This LVL may be explained by the accumulation of the ancient oceanic crust above the ' 660 ' found beneath China.

Acknowledgments. We are grateful to two anonymous reviewers for their detailed comments on the manuscript, which improved it tremendously. Our work is supported by the National Science Foundation of China (Grant 40574024 and 40374009). Part of the research was conducted while the first author was visiting at the Earthquake Research Institute, the University of Tokyo. The seismic wave data were supplied by China Earthquake Network Center of the Chinese Earthquake Administrator, Dr. Li and Dr. Yuan of GFZ provided assistance with the moveout of ORFs, and Dr. Zhang (GUCAS) provided assistance with the computations on the environment. Drs. Kumar and Tonegawa of ERI provided many helpful comments on the drafts. The authors gratefully acknowledge all of these individuals.

\section{References}

Ai, Y., T. Zheng, W. Xu, Y. He, and D. Dong, A complex 660 km discontinuity beneath northeast China, Earth Planet. Sci. Lett., 212, 63-71, 2003.

Ammon, C. J., The isolation of receiver effects from teleseismic P waveforms, Bull. Seismol. Soc. Am., 81, 2504-2510, 1991.

Bassin, C., G. Laske, and G. Masters, The current limits of resolution for surface wave tomography in North America, EOS Trans. AGU, 81, F897, 2000.

Dziewonski, A. M. and D. L. Anderson, Preliminary reference Earth model, Phys. Earth Planet. Inter, 25, 297-356, 1981.

Efron, B. and R. J. Tibshirani, An introduction to the Bootstrap, 436 pp., Chapman \& Hall, 1998.
Fukao, Y., S. Widiyantoro, and M. Obayashi, Stagnant slabs in the upper and lower mantle transition region, Rev. Geophys., 39, 291-323, 2001.

Grand, S. P., Mantle shear-wave tomography and the fate of subducted slabs, Philos. Trans. R. Soc. Lond. A, 360, 2475-2491, 2002.

Gudmundsson, O. and M. Sambridge, A regionalized upper mantle (RUM) seismic model, J. Geophys. Res., 103, 7121-7136, 1998.

Hafkenscheid, E., M. J. R. Wortel, and W. Spakman, Subduction history of the Tethyan region derived from seismic tomography and tectonic reconstructions, J. Geophys. Res., 111, B08401, doi:10.1029/ 2005JB003791, 2006.

Huang, J. and D. Zhao, High-resolution mantle tomography of China and surrounding regions, J. Geophys. Res., 111, B09305, doi:10.1029/ 2005JB004066, 2006.

Karato, S., Importance of inelasticity in the interpretation of seismic tomography, Geophys. Res. Lett., 20, 1623-1626, 1993.

Karato, S., On the separation of crustal component from subducted oceanic lithosphere near the $660 \mathrm{~km}$ discontinuity, Phys. Earth Planet. Inter., 99, 103-111, 1997.

Karato, S., The dynamic structure of the deep earth: an interdisciplinary approach, 241 pp., Princeton University Press, Princeton and Oxford, 2003.

Kennett, B. L. N. and R. E. Engdahl, Travel times for global earthquake location and phase identification, Geophys. J. Int., 105, 429-465, 1991.

Langston, C. A., Structure under Mount Rainier, Washington, inferred from teleseismic body waves, J. Geophys. Res., 84(B4), 4749-4762, 1979.

Lebedev, S. and G. Nolet, Upper mantle beneath Southeast Asia from $S$ velocity tomography, J. Geophys. Res., 108, doi:10.1029/2000JB 000073, 2003.

Lebedev, S., S. Chevrot, and R. D. van der Hilst, The 660-km discontinuity within the subducting NW-Pacific lithospheric slab, Earth Planet. Sci. Lett., 205, 25-35, 2002.

$\mathrm{Li}, \mathrm{X}$. and X. Yuan, Receiver functions in northeast China-implications for slab penetration into the lower mantle in northwest Pacific subduction zone, Earth Planet. Sci. Lett., 216, 679-691, 2003.

Li, X., S. V. Sobolev, R. Kind, X. Yuan, and C. H. Estabrook, A detailed receiver function image of the upper mantle discontinuities in the Japan subduction zone, Earth Planet. Sci. Lett., 183, 527-541, 2000.

Ligorria, J. P. and C. J. Ammon, Iterative deconvolution and receiverfunction estimation, Bull. Seismol. Soc. Am., 89, 1395-1400, 1999.

Niu, F. and H. Kawakatsu, Complex structure of the mantle discontinuities at the tip of the subducting slab beneath the northeast China: a preliminary investigation of broadband receiver functions, J. Phys. Earth, 44, 701-711, 1996.

Niu, F. and H. Kawakatsu, Determination of the absolute depths of the mantle transition zone discontinuities beneath China: effect of stagnant slabs on mantle transition zone discontinuities, Earth Planets Space, 50, 965-975, 1998.

Shen, Y. and J. Blum, Seismic evidence for accumulated oceanic crust above the 660-km discontinuity beneath southern Africa, Geophys. Res. Lett., 30(18), 1925, doi:10.1029/2003GL017991, 2003.

van Keken, P. E., S. Karato, and D. A. Yuen, Rheological control of oceanic crust separation in the transition zone, Geophys. Res. Lett., 23, 18211824, 1996.

Yang, Y. and H. Zhou, Application of receiver function method to estimate the buried depths of discontinuities in the upper mantle beneath china and adjacent area, Chinese, J. Geophys., 44(6), 783-792, 2001.

Yuan, X., J. Ni, R. Kind, E. Sandvol, and J. Mechie, Lithospheric and upper mantle structure of southern Tibet from a seismological passive source experiment, J. Geophys. Res., 102(B12), 27491-27500, 1997.

Zhao, D. and J. Lei, Seismic ray path variations in a $3 \mathrm{D}$ global velocity model, Phys. Earth Planet. Inter., 141, 153-166, 2004.

X. Shen (e-mail: shenxzh@gmail.com), H. Zhou, and H. Kawakatsu 